\title{
7 What Can Europe Learn From Silicon Valley Accelerators?
}

Accelerators can greatly contribute to advancing a dynamic European startup economy. This study has examined 23 accelerators in Silicon Valley with the aim of inferring some lessons on how to create a stronger and more vibrant startup community in Europe. In addition to presenting the main conclusions of my study, I outline ten practical decision rules for aspiring European accelerators that I believe will ensure their effectiveness. These ten rules are based on my chief findings from this study. I conclude the book by sharing some thoughts on the substantial role that accelerators can play in boosting Europe's startup economy.

\section{Main findings and lessons}

Silicon Valley's remarkable track record as a global innovation and startup hotspot never ceases to amaze the rest of the world. The region has become a paragon for policymakers, innovation stakeholders, ambitious entrepreneurs, and hungry startup founders. Its track record is based on a consistent and resilient ecosystem that secures access to talent, venture capital, support facilities, and a willing government. Its performance is driven by a culture that stimulates big thinking, sharing, competition, and risk-taking. Silicon Valley has launched startups that grew into companies that have changed our way of communicating, our lifestyle, and even the world. Apple, Google, Facebook, Twitter, WhatsApp, Instagram, Uber, and Airbnb are prominent examples. But it is also a region where there is significant inequality between insiders and outsiders, between high-tech nouveau riches and underprivileged social groups. For many members of the lower and middle class, Silicon Valley is no longer a place they can afford to live in. This is the painful downside of the Valley's success story.

During the last five to ten years, Silicon Valley has witnessed a rapid increase in accelerators helping startups to develop and grow their business. These 'schools of startup entrepreneurship' assist new ventures to sharpen their business concept, to calibrate their business model, to get first customers and traction, to pitch to angel investors and VCs, and, most importantly, to scale their venture. Silicon Valley's math is all about fast growth. In this study, I attempt to understand the role that accelerators play 
in taking startups to the marketplace, in expanding their market impact, in helping them to get traction and to scale up, and in bringing them to the next round of funding. I do so in the hope that European countries can learn from the Silicon Valley accelerator phenomenon in order to bridge the entrepreneurial divide and innovation gap between Europe and the U.S.

I interviewed 23 accelerators from all over Silicon Valley, which provided me with considerable insight into how these 'growth engines' operate and how they approach the puzzle of accelerating the life cycle of innovative startups. More specifically, I looked at accelerators' mission and philosophy, technology focus and target group, business model, admittance procedures, cooperation networks, program content, and mentoring as well as the main challenges they face and their plans for the future.

Accelerators are in great demand among startup founder teams, as the latter understand that participation in these growth programs will improve their market opportunity and investment chances. Accelerators, in turn, are highly selective in admitting startups. Only the best and brightest teams are accepted, based on stringent selection procedures. The right combination of team, technology, and market is paramount. In general, Silicon Valley accelerators do not admit solo founders because the risk of failure is simply too high. Running a startup is extremely demanding and requires multiple skills and competences that are seldom incorporated in one single person. Running an accelerator is equally demanding and in many cases resembles launching and growing a startup, with all the complexities and struggles it takes.

Accelerators in Silicon Valley vary significantly in terms of key features such as mission, business model, size, program structure, and mentoring. I observed a chief dichotomy between general/low-touch accelerators and specialized/high-touch (domain-specific and niche) accelerators. This distinction turned out to be very helpful in explaining the differences between accelerators.

On one side of the continuum, we have large general accelerators that do not focus on one specific technology or target group but accept startups across a broad spectrum of technologies. To add substance, accelerators may introduce so-called 'verticals' (single technologies), e.g., health, mobility, robotics. These accelerators are primarily interested in volume, i.e., in preparing large numbers of startups for commercial take-off. Their investment logic is based on the assumption that a few successful startups will raise significant accelerator revenue that will make up for the losses of most others. These accelerators tend to have strong links with the VC community. Accelerators typically offer short, standardized growth programs (three to four months) to several startup classes a year. Mentoring is part of the 
program but on a low-intensity basis (low-touch). The program usually culminates in a demo day where startups will present their prototypes to investors. Taking equity is a common investment policy among these accelerators. In many cases they operate as investment vehicles: their business model is to find startups that will be mega-successful - the "next big thing". For many outside observers, these general/low-touch accelerators represent the mainstream accelerators. Well-known examples are Plug and Play and 500 Startups.

On the other side of the continuum, we find specialized/high-touch accelerators. These are smaller accelerators that focus on bringing a limited number of startups to the market. They concentrate on particular technologies (for example artificial intelligence, cloud infrastructure, mobile) or niche markets (solar, clean technology, water) and actively coach their startups in a very hands-on (high-touch) way. The startups are not organized into classes, as they are mostly accepted on a rolling basis. They are not provided with standardized growth programs, and the length of in-house coaching is not fixed. These accelerators' ROI strategy and equity policy depend on their mission: some specialized/high-touch accelerators are for-profit (e.g., The Hive, Powerhouse), while others are non-profits (Imagine $\mathrm{H}_{2} \mathrm{O}$, CleanTech, and Women's Startup Lab).

It should be noted that this differentiation between the two accelerator types does not necessarily correspond to the distinction between commercial and mission-driven accelerators. Though most general/low-touch accelerators are for-profit companies, there is a mixed pattern among specialized/high-touch accelerators. And in any case, quite a number of for-profit accelerators are managed by highly content-driven executives who all share a passion for making an impact.

A third category of startup growth facilitators are accelerating platforms. They primarily offer office or lab space to startups, but they may also arrange access to VCs and provide elementary business support. They do not see themselves as investors but generally work together with the corporate world. These platforms offer startups a stimulating environment in which to grow. Examples include RocketSpace and Runway.

Accelerators also differ with respect to their market focus in terms of $\mathrm{B}_{2} \mathrm{~B}$ or $\mathrm{B}_{2} \mathrm{C}$, software or hardware. These choices obviously directly affect the way that accelerators are organized (selection, program, mentors, funding) and the resources they need (e.g., engineering expertise, hardware lab, suppliers). Hardware accelerator HAX differs completely from software accelerator TiE LaunchPad, even though both accelerators target enterprisefocused startups. 
Mentoring startups is what all accelerators see as their core activity, either high-touch or low-touch. The Silicon Valley pool of mentors coaching accelerator startup teams is phenomenal. All the executives I interviewed stress that there is no shortage of committed and experienced mentors. This appears to be part of the Valley's culture of giving back. Mentors are often former entrepreneurs who want to share their expertise and networks and enjoy being involved in the valorization of new technologies. They give their counseling for free. But their motives are not per se purely altruistic, as they may have a personal interest in helping startups go to market. Access to gifted startup mentors is what makes an accelerator. In the specialized, smaller high-touch accelerators, startups are coached - on a day-to-day basis - by accelerator executives. A perfect mentor-startup fit is imperative.

Accelerators offer a range of programs for their startups, depending on their mission and focus. Program formulas differ in length, intensity, standardization, and coaching offered. Some programs are cohort-based (which is usually the case with larger general accelerators), while others are tailor-made (which tend to be seen at smaller, domain-specific and niche accelerators). But all programs and coaching activities share a core that is relevant to all startups. Founder teams need to develop their business idea, to figure out the growth and scalability options, work out their business model and company strategy, come up with a marketing plan, prepare themselves for go-to-market, get first customers and sales, pivot their product and strategy based on market responses, work out team issues, pitch to venture capitalists, and cope with the many practical issues that startups face. Accelerators help startup teams in addressing these issues and making their business stronger.

Silicon Valley accelerators excel in organizing events, reflecting their active involvement in the startup community. Workshops, lectures, speaker sessions, seminars, tutorials, roundtables, and founder team presentations are all part of the services that accelerators offer to their startups. All this adds to a vivid, inviting, and entrepreneurial accelerator culture.

All accelerator executives agree that predicting startup success is often more about intuition, hindsight, and lots of luck than about proven quantitative models. It's not just team, technology, or market that leads to success, but it is clear that having a malfunctioning team, weak technology, and no traction will more than likely lead to failure.

Accelerators work with outside partners, mostly on an informal basis, sometimes in a more structured way. Collaboration with investors is a top priority, as it gives them access to funding. And investors have a clear interest in being involved with accelerators: it brings them into contact with 
the most talented startups and promising new technologies. Accelerators also cooperate with other agencies within the Silicon Valley ecosystem: universities, innovation and industry stakeholders, and the corporate world. Lawyers are particular useful in giving legal and business advice to startup teams. They often work on the basis of deferred fees, meaning that startups will be charged when revenues come in and not earlier. This greatly helps startups in the early stages of the business cycle.

A trend can be observed in which large corporates start their own in-house accelerators. This keeps them in touch with innovative ideas and with new technology that can stimulate their business activities and market - maybe not today but probably tomorrow. Moreover, by bringing in startups into their labs and research centers, they can energize their innovation and entrepreneurial corporate culture. Samsung NEXT is an example of a corporate accelerator.

There were a number of similarities in the responses given by the interviewees regarding the challenges they face and their plans for the future. They all underline the importance of having a unique selling point that separates them from the competition, of getting the right startup teams at the right moment, of optimizing the number of startups, and of achieving a fair number of winners. Talent is probably the main concern cited by the accelerator executives. Mission-driven accelerators feel the permanent need to balance purpose and professionalization.

Interestingly, nearly all accelerators are involved in trajectories to internationalize their organizations and to reach out to other continents and countries. Some have very concrete plans, while others are still considering the modalities (e.g., franchising, new branches, co-branding, hubs). Pioneering Silicon Valley accelerators that have already entered the European market include Plug and Play and RocketSpace. Most Silicon Valley accelerators, it has to be stressed, are very international in that the startup teams they coach come from all over the world.

A final word on accelerator success: most accelerators in Silicon Valley are relatively young companies that lack a balanced and validated set of performance metrics. They tend to illustrate their success by pointing to the funds that 'their' portfolio startups have collectively raised after leaving the accelerator. This fundraising algebra - also known as 'vanity metrics' - may look quite impressive but needs some serious debunking. This especially holds true for the larger, general/low-touch accelerators. The main issue, naturally, is whether there is a causal relationship between accelerator participation and startup success. We need much stronger empirical evidence. Developing and reporting solid performance 
indicators should be a major priority for professional accelerators. This is particularly true given that new accelerators are popping up on an almost daily basis.

\section{Bridging Europe's innovation gap}

European policymakers agree that, in comparison to the United States, Europe is lagging behind in innovation, entrepreneurship, and new venture creation. Data indicate that the U.S. outperforms Europe in terms of R\&D spending, the number of new businesses and first-time entrepreneurs, the available amount of venture capital, and the number of fast-growing companies (scale-ups). It also imposes less bureaucracy on startups (Entrepreneurship 2020; Ester \& Maas 2016; European Investment Bank 2016; Horizon 2020). The nature of the entrepreneurial divide between both continents is rooted not only in institutional differences but also in cultural factors. Europe is more risk-averse, and entrepreneurial ambition is less applauded. For many Americans - certainly those living in Silicon Valley - successful startup founders and serial entrepreneurs are celebrated role models.

The U.S. ecosystem for startups, and in particular the Silicon Valley version, is more elaborate and balanced with respect to access to funding, talent, support networks, and government facilitation. It has a much longer tradition, too. What is equally relevant is that the system is grounded in a strong entrepreneurial spirit; its culture breathes risk-taking and excellence. I know that these conclusions sound rather general, but their truth is not disputed. Just think for a moment: would it have been possible for Google, Apple, Facebook, Uber, or Airbnb to have been European companies? In terms of ideas, maybe; in terms of commercialization, probably not.

European policymakers have become concerned about Europe's innovation gap: compared to the United States, the Old World is less adept at taking innovations to market. As Jyrki Kaitanen, European Commission Vice President for jobs, growth, investment and competitiveness, stated: "Europe has been good at turning Euros into knowledge, but not that good at turning the new knowledge into Euros and jobs." ${ }^{91}$ There is a gap between inventiveness and marketability, between brilliant ideas and market response, between innovation and commercial implementation. American startups are much more focused on valorizing their innovations, on bridging the innovation gap - in simple terms, to make money out of innovation. As we have seen, all the incentives and parameters of the Silicon Valley ecosystem converge to help bring innovations to the market. Accelerators play a pivotal role in this. 
Some Silicon Valley gurus are quite gloomy about Europe's potential to turn the tide. Veteran technology investor and PayPal founder Peter Thiel is one of them. Though it has not prevented him from investing considerably in high-tech European startups, Thiel was brutally critical of Europe's lack of innovativeness and entrepreneurship in a 2014 interview with the Financial Times: "I think people in Europe are generally pessimistic about the future. They have low expectations, they're not working hard to change things. When you're a slacker with a pessimistic view of the future, you're likely to meet those expectations." ${ }^{\prime 92}$

In his book Zero to one, also published in 2014, Thiel typifies Europeans as "indefinite pessimists". ${ }^{93}$ Coincidence or not, in the same year the European Commission launched Horizon 2020, the largest EU research and innovation program ever with nearly $€ 80$ billion of funding available over seven years (2014 to 2020).

The main goal of Horizon 2020 is to boost Europe's global innovativeness and competitiveness: "It promises more breakthroughs, discoveries, and world-firsts by taking great ideas from the lab to the market." (Horizon 2020:1). This is a sentence that could have been penned in Silicon Valley. The program links research to innovation and is focused on excellent science, industrial leadership, and the tackling of major social issues. The program aims to re-establish Europe's position in producing world-class science and to remove unnecessary red tape that hinders innovation. Enabling funding for premier research is the key pillar of Horizon 2020. The areas covered include nanotechnologies, advanced materials, biotechnologies, IT, space, health, food, agriculture, forestry, energy, transport, and climate action. The number of proposals that were submitted under the program's first 100 calls was 36,$732 ; 14 \%$ of which were retained for funding. Horizon 2020 has turned into the main and largest European funder of research and innovation, with a strong emphasis on bridging the innovation gap. And, importantly, the market potential of innovations is a basic funding criterion.

Just prior to the Horizon program, the EC launched its Entrepreneurship 2020 Action Plan. The new initiative is based on the realization that in order "to bring Europe back to growth and create new jobs, we need more entrepreneurs." (Entrepreneurship 2020:3). The idea is to "unleash" Europe's entrepreneurial potential, remove barriers, and accelerate its entrepreneurship culture. The program consists of three action pillars:

a) Entrepreneurial education and training to support growth and business creation (increasing and improving practical entrepreneurial learning, especially within higher education); 
b) The creation of an environment in which entrepreneurs can flourish and grow (better access to finance, early-stage investors, and alternative funding; tax incentives; better use of ICT; easier business transfers; making bankruptcy less insuperable for second starters; simpler rules for startups; access to incubators and business accelerators);

c) The development of role models in order to reach out to specific groups (entrepreneurship promotion; becoming an entrepreneur as a regular career choice; and stimulating startups among women, seniors, migrants, the unemployed, and young people).

Each of the three pillars is translated into a number of specific policy proposals and recommendations for the individual EU member states. It is one of the first EU documents that mentions the role of accelerators in building new ventures, albeit only briefly.

One further EU initiative needs to be mentioned that is allied to the Entrepreneurship 2020 program: Startup Europe. ${ }^{94}$ Its main goal is to strengthen the European business environment for tech entrepreneurs by providing access to support services such as business advice, networking, and legal assistance. Startup Europe aims to inspire the business community, acknowledge role models, and celebrate new and innovative startups. It launched the Accelerator Assembly, which operates as Europe's prime network for startup accelerators. ${ }^{95}$ The Assembly is an industry-led network to connect accelerators all over Europe and to act as "a forum delivered by the accelerator community, for the accelerator community." The forum shares information on key trends in the world of tech accelerators, exchanges best practices on startup growth programs, organizes meetings and conferences, and publishes guides to European accelerator programs. The target group is the leaders of accelerators that help founder teams to build and grow their business.

Until very recently, Europe was well behind the U.S. - and certainly behind Silicon Valley - in making the transition to a startup economy. But in the last few years, Europe has taken a leap forward, launching a number of programs designed to encourage entrepreneurship and fuel an entrepreneurial culture. Much still needs to be done, and it needs to be done in a way that is consistent with basic European values and social preferences. Europe must find its own way towards a flourishing startup economy; it cannot 'copy \& paste' the Silicon Valley model. Individual European countries are working hard to build ecosystems that, with the help of accelerators, will become fertile environments for startups to blossom. Cities such as London, Berlin, Stockholm, Paris, Amsterdam, Barcelona, Madrid, and many 
others are becoming fine examples of energetic startup hubs. ${ }^{96}$ The fact that Silicon Valley investors are actively investing in European startups is a case in point. But there still is a long way to go, if only because individual European countries differ markedly in their approach to addressing the innovation gap (Veugelers 2016) and implementing policies promoting entrepreneurship and startups. In the next section, I look at the startup climate in a European country I know best: the Netherlands.

\section{The Netherlands: StartupDelta}

In the last five to eight years, the startup scene in the Netherlands has developed rapidly and it is now turning into a mature economic community that fosters innovation and entrepreneurship. Launching viable startups is a high priority on the Dutch economic policy agenda. People in the Netherlands understand that startups add to the competitiveness of the Dutch economy, particularly if startups are able to make the transition to fast-growing scale-ups. Successful Dutch startups with a global significance include Ayden, WeTransfer, Booking.com, and TomTom. Some fast-growing runner-ups include Catawiki, Takeaway.com, Elastic, Gitlab, and Picnic.

There are a number of flourishing startup hubs in the Netherlands, particularly in the Eindhoven area (Philips High Tech Campus, ASML, NXP, FEI), the Rotterdam region (seaport-related innovation, logistics, and clean technology), the Wageningen area (food and agriculture), Delft University (engineering and hardware), and Amsterdam (the center of Dutch venture capital). The 2017 Global Startup Ecosystem Report lists Amsterdam in the top 20 of worldwide best-performing startup cities and habitats (Silicon Valley being number one). Only four other European cities rank higher: London, Berlin, Paris, and Stockholm.

In 2014, StartupDelta was launched to advance, coordinate, and promote the Dutch startup ecosystem. It was first led by Special Envoy and former EC Commissioner Neelie Kroes, followed in 2016 by Prince Constantijn of Orange-Nassau - the younger brother of the Dutch monarch WillemAlexander - who is an acclaimed aficionado of startups and new technology. A publicly backed initiative, StartupDelta's aim is to make the Netherlands the best-connected and largest startup ecosystem in Europe. The initiative brings together the government, the corporate world, startups, universities and research labs, and investors. The mission according to Dutch Prime Minister Mark Rutte is the shared goal of "making the Netherlands an ideal location for startups, where young entrepreneurs with futuristic ideas 
can turn their dreams into reality. ${ }^{97}$ StartupDelta has introduced startup visas for foreign startup founders, initiated a so-called corporate launch pad, and is involved in informing companies from abroad how they can grow their business in the Netherlands.$^{98}$ Recently, it convinced the Dutch government to introduce fiscal incentives to invest in startups and to lower startup labor costs.

Encouraging close collaboration between corporates and startups is a priority of StartupDelta. To further this goal, in 2016 the COSTA (COrporates and STArtups) program was launched by Special Envoy Neelie Kroes together with Jan Kees de Jager, CFO of KPN and former Dutch Minister of Finance. "The reasoning is that collaboration between nimble startups and corporates that have scale and leverage will accelerate the pace of innovation in the Netherlands. ${ }^{99}$ As part of this long-term program, 19 Dutch corporate giants (including Shell, Philips, ASML, Unilever, Rabobank, KPN, AkzoNobel, and KLM) committed themselves to jointly enter partnerships with more than 300 startups within a period of less than one year. ${ }^{100}$ The underlying idea of this major initiative was to boost the innovative power of the Netherlands, deepen its ecosystem, promote lasting cooperation between the corporate world and startups, and accelerate sustainable economic growth.

In 2017, StartupDelta introduced a new Action Plan that seeks to connect and promote the Dutch startup ecosystem as one single hub. It also published a Startup Manifesto with a number of policy priorities to make the Netherlands the startup country in Europe. The plan sets a number of objectives: to grow the overall pool of top-tier foreign venture capital and 'smart funding' by making the Dutch fiscal system more competitive internationally, to link Dutch startups to the rest of the world through trade missions and international hubs, to connect and improve national and international mentoring networks, to link startups and corporates, to legally allow for an online procedure for new ventures to start their businesses, to make education more entrepreneurial, to enlarge the talent pool, and to address the pressing shortage of tech talent. Proposed actions also emphasize the need for less stringent regulations on new technology, a more active role for the government as a launching customer for startups, a more flexible labor market to hire startup employees, and a system to challenge and reward universities for launching spin-outs and boosting startups. The Action Plan specifies the new goals as concretely as possible and includes targets for operational key performance indicators (KPIs).

The Action Plan and the Startup Manifesto's focus on attracting more foreign venture capital and on enlarging the startup talent pool is 
understandable. The latest Global Startup Ecosystem Report, mentioned above, indicated outstanding performance metrics (e.g., exit values) for the Amsterdam-StartupDelta, but as the Report concludes, "it could generally improve access to talent and funding" (2017: 76). But, it has to be added, it is not merely a case of re-adjusting the institutional parameters of the ecosystem. Culture also matters. The Netherlands could do a better job of growing new companies with a global impact. As Dutch startup ambassador Prince Constantijn makes clear: "We sometimes lack a sense of urgency. We need to fuel our entrepreneurial drive, the desire to be the best. At the same time, startups often feel they're left to fend for themselves. Their financing comes from venture capital funds in the U.S. People over there sometimes have a better idea of who's doing well here than we do!"101

Though StartupDelta is not an accelerator program, it prides itself in acting as a gateway to accelerators and other ecosystem facilitators in the Netherlands. The country has a number of reputed incubators and accelerators such as YES!Delft (2005), Rockstart (2012), Startupbootcamp (2010), whose growth programs incorporate many elements of their Silicon Valley role models, particularly with respect to startup selection, technology focus, team composition, program format, mentoring, access to investors, and corporate partnerships. For many new Dutch accelerators, top Silicon Valley accelerators are leading examples of how to execute startup growth programs.

\section{Accelerator decision tool: Ten basic questions}

Accelerators, as we have seen, come in all shapes and sizes. Though they all strive for startup development and growth, they are based on different philosophies, different investment strategies, and different business missions. Accelerators help startups to refine and scale their business proposition and to define their go-to-market options but do so in a variety of ways. Their growth programs differ in structure, technology focus, target group, size, recruitment, coaching, and mentoring. Accelerators, moreover, vary in terms of business model and equity policy. A differentiation that turned out to be instrumental in my study is the one between general/lowtouch accelerators, specialized/high-touch accelerators, and accelerating platforms. This differentiation clearly reflects these different organizational parameters.

Based on my findings and analysis of the 23 Silicon Valley accelerators in this study, I have formulated ten basic questions that should facilitate 
entrepreneurs, innovation stakeholders, and policymakers in Europe and elsewhere intending to design and build an accelerator. This is a simple but fundamental decision tool that crystallizes the raison d'être of every accelerator wanting to coach, launch and grow successful startups. These guidelines are solidly grounded in the main findings of my research.

It should be noted that, by its nature, launching an accelerator does not fundamentally differ from launching a startup. As a consequence, most of the rules that apply to building a startup pertain to building an accelerator as well.

In the coming years, the number of new accelerators in Europe will most certainly increase rapidly. My hope is that the following decision tool will be instrumental in helping them set up their business in a professional and appealing way - one that takes into account the experience of Silicon Valley accelerators.

1. Mission: for-profit or non-profit?

The first question is whether the accelerator's main goal is to make money or whether it is primarily mission-driven without the sole intention of being profitable. Some accelerators are first and foremost interested in growing startups that will generate handsome revenues, while others are inspired by the need to solve urgent social problems. The first objective implies recruiting startups that are high-growth traction potentials; the second objective leads to searching for startups that could have a major societal impact. It should be emphasized that in reality there is a gray area between these two opposite ends of the spectrum. But choosing one or the other of these two principal objectives will predetermine an accelerator's ROI strategy, startup selection process, stakeholder involvement, and equity policy - in short, its business model.

2. Focus: general or niche market?

The next basic question to ask is whether the accelerator will take a technology-agnostic approach to growing innovative startups or whether it will focus on specific technologies (e.g., mobility, artificial intelligence, health) or niche markets. This choice directly affects an accelerator's recruitment process, coaching programs, investor profiling, and stakeholder participation. A tendency I observed among the larger Silicon Valley general accelerators was to include specific verticals that add to incremental specialization. Niche players tend to be smaller, though they can be larger in domains such as clean 
technology. Smaller niche accelerators are typically characterized by hands-on coaching of startup teams. An additional issue is whether the accelerator's market focus will be on $\mathrm{B}_{2} \mathrm{C}$ or $\mathrm{B} 2 \mathrm{~B}$ (or a combination of both) and whether it will be oriented towards software or hardware.

3. How selective?

The answer to this question should already be obvious: accelerators by definition need to be highly selective in their startup recruitment policy, irrespective of their main goal or mission. Only startups that have the right mix of ambition, passion, and business idea sophistication should make the cut. The bar needs to be set high. Quality is decisive, distinctiveness is indispensable, and competitiveness is essential. Without exception, Silicon Valley accelerators have rigid admittance policies which they take very seriously. It would be illadvised for accelerators on the European side of the Atlantic to set lower recruitment standards.

4. Target group: team or solo entrepreneurs?

Here, too, the answer should be quite straightforward. As almost all my interviewees emphasized, startup teams are to be preferred over solo founders. Combining all startup roles - product development, marketing, sales, customer issues, investor relations, day-to-day management, personnel hiring - into one person is bound to fail. Silicon Valley accelerators are quite outspoken in favoring balanced teams, and team assessment is consequently a standard part of the selection process. Their general experience is that successful startups are led by strong teams.

5. Cohorts or rolling admittance?

The next decision is whether to have startups participate in the new accelerator program as cohorts (over a fixed time period) or on a rolling basis. As we have seen, larger accelerators that let in substantial numbers of startups tend to be organized in terms of cohorts or batches. These startups enter the acceleration program as a class, which 'graduates' on demo day. Smaller accelerators, especially niche players, are likely to admit a limited number of startups on a continuous basis.

6. Structured program?

Related to the previous question is whether startup teams are offered a structured growth program or tailor-made coaching. Accelerator 
size is also critical in this case. Larger accelerators work with highly structured programs, while smaller accelerators focus on empowering individual teams. But the underlying issues that are covered in the program or coaching are, of course, highly comparable: how to create a smart, scalable, and viable business model, how to build a feasible demo, how to get traction, how to solve team challenges. Another decision that must be made is which parts of the program can be offered in-house and which parts remotely, i.e., online. The role of new communication technology can facilitate this decision. Monitoring the effectiveness of accelerator programs should also be a priority.

7. Mentorship: highly intensive or less intensive?

Every new accelerator must invest significantly in a substantial pool of committed and experienced mentors. The size of the accelerator is relevant here. In large accelerators with sizeable cohorts, mentoring tends to be less intensive (and shorter) compared to smaller niche accelerators that deliberately focus on a restricted number of startup teams. These smaller accelerators have highly intensive mentoring, with coaches working side by side with their teams in all crucial phases of startup development. Larger accelerators tend to work with mentors from outside, while smaller accelerators use internal coaches.

8. Role of investors?

One of the most important challenges for a new accelerator is creating a close network of investors that are looking for promising startups. Accelerators need to have financial resources of their own to bring promising startups to the marketplace, but they also must have a strong panel of angels and VCs willing to invest in talented startup teams and to bring scalable business ideas to the next round of funding. Accelerators that have no structural connections to investors will not last long. A fair and accountable relationship between equity percentage, investment, and accelerator program magnitude needs to be agreed upon.

9. Specialized startup support?

It is good policy for new accelerators (including accelerating platforms) to offer startups a range of support facilities such as legal advice, counseling on human resources management, ICT services, administrative expertise, and financial assistance. Silicon Valley has a strong reputation in this respect. This kind of support helps startup teams 
to professionalize their new business venture and to avoid pitfalls. It also adds to the practical relevance of an accelerator's portfolio of services.

10. Culture: office space or startup vibe?

An inspiring accelerator must have the right culture to cultivate innovation, openness, sharing, entrepreneurship, and excellence - a challenging culture that is both dynamic and stimulating. Silicon Valley accelerators set an outstanding example in this respect. An accelerator or an accelerating platform is not just shared office space, not just bricks and mortar - it is much more than that. It must resonate shared dreams, shared ambitions, and shared passions. The accelerator can realize this by organizing an exciting variety of events, seminars, expert talks, pitching classes, happy hours, and dream sessions.

These ten questions incorporate the conclusions I have drawn from the experiences of accelerators based in Silicon Valley. I believe that in applying this decision tool, new accelerators in Europe will be encouraged to think in a more structured way about the precise formats that suit their mission and objectives.

\section{Final thoughts}

My study has shown that accelerators are a vital part of Silicon Valley's highly successful ecosystem. As dedicated 'schools of entrepreneurship', they help startups to develop, launch, and scale their new venture. These accelerators are in great demand by ambitious startup founding teams, also by international teams from outside the U.S. Although the metrics used to measure accelerators' success need to be further developed and validated, the impact that accelerators can have is clear. Their secret, I conclude, is that they operate as intelligent, micro-ecosystems that reinforce cultural and institutional factors that are necessary for new business acceleration such as the right mindset, the right team, and the right business idea, coupled with access to engaged mentors, investors, stakeholders, and talent and backed up by a well-functioning startup support system.

If Europe is serious about revitalizing its economic competitiveness, rejuvenating its commercial innovation performance, and elevating its entrepreneurial leadership, it must dedicate itself to investing in (forprofit and non-profit) startup accelerators. This is a joint responsibility of 
industrial stakeholders, innovative entrepreneurs, enterprising universities, and facilitating governments. Europe is already moving in the right direction, but much more needs to be done. One could say that the European startup agenda itself needs rapid acceleration.

Accelerators can play a distinct role in furthering European countries' ambitions to become thriving startup nations. As the Silicon Valley story shows, accelerators can make all the difference in this respect. They foster innovation, entrepreneurship, and help startups to take great ideas to the market. These are the three buzzwords that should inspire Europe in making the necessary transition to a resilient and sustainable European startup and scale-up economy that will define the $21^{\text {st }}$ century. In doing so, Europe will be securing a solid economic future for itself. 